\title{
$\infty$ \\ Saudação ao Professor Marc Gentilini, EM SUA POSSE COMO HONORÁRIO ESTRANGEIRO DA

\author{
Academia Nacional de Medicina, \\ EM 28 DE OUTUBRO DE 202 I
}

BienVEnue au Professeur MarC GENTILINI, LORS DE SON INVESTITURE COMME HONORAIRE ÉTRANGER DE L'ACADEMIA NACIONAL DE MEDICINA, LE 28 OCTOBRE 2021

\author{
por / par \\ Cláudio Tadeu Daniel-Ribeiro \\ Membro Titular, Academia Nacional de Medicina \\ malaria@fiocruz.br
}

Excelentíssimo Senhor Presidente da Academia Nacional de Medicina Acadêmico Rubens Belfort Mattos Júnior,

Excelentíssimo Senhor Secretário Geral - Acadêmico Carlos Eduardo Brandáo,

Senhoras e Senhores Acadêmicos,

Senhoras e Senhores convidados,

Meu querido mestre e amigo Professor Marc Gentilini

Estamos aqui reunidos para celebrar a posse do Professor Marc Gentilini como
Honorário Estrangeiro da Academia Nacional de Medicina.

Agradeço ao Senhor Presidente Acadêmico Belfort Mattos Júnior por me designar para a honrosa tarefa de saudar meu mestre e amigo. Je vous demande, Monsieur Gentilini, de m'excuser, pour ces quelques mots que je dirai en Portugais à mes confrères et consoeurs au sujet de votre carrière, avant de passer à mon message d'accueil. Peço desculpas às Senhoras e Senhores Acadêmicos de nossa Casa por me dirigir ao Professor Gentilini em francês, mais adiante. ${ }^{1}$ 


\section{$\sim 104 \approx$

Marc Gentilini nasceu em 31 de julho de 1929 em Compiègne. Cursou o ensino secundário no Colégio Jesuíta de Reims, onde também iniciou a Faculdade de Medicina, mais tarde seguida pelo externato e internato em medicina interna nos Hospitais de Paris. Tornou-se assistente em parasitologia, fez seu serviço militar na Argélia, Sudão Francês (atual Mali) e Senegal. Chefe de Clínica e Assistente dos Hospitais de Paris, foi nomeado Professeur Agregé de Microbiologia, em 1966 e exerceu nos Hospitais Claude Bernard e Saint-Louis, antes de ser designado para o Hospital Pitié-Salpêtrière, em 1970, onde criaria o Departamento de Doenças Infecciosas e Tropicais, e o Laboratório Central de Parasitologia e Micologia, especialmente voltados para os países em desenvolvimento. Gentilini chefiaria até a sua aposentadoria em 1997, esse conjunto de disciplinas, reforçado com a criação do Instituto de Saúde e Desenvolvimento. $\mathrm{Na}$

${ }^{1}$ Votre Excellence le Président de l'Academia Nacional de Medicina - Académicien Rubens Belfort Mattos Júnior,

Votre Excellence le Secrétaire général - Académicien Carlos Eduardo Brandão,

Mesdames et Messieurs les Académiciens,

Mesdames et messieurs les invités,

Mon cher maître et ami Professeur Marc Gentilini

Nous sommes réunis ici pour célébrer l'investiture du professeur Marc Gentilini en tant que Membre Honoraire Étranger de l'Academia Nacional de Medicina.

Je remercie, Monsieur le Président Académicien Belfort Mattos Júnior de m'avoir confié la tâche honorable de saluer mon Maître et ami. Peço-lhe, Professor Gentilini, que me desculpe, por essas poucas palavras introdutórias que direi aos meus colegas em português sobre a sua carreira, antes de passar aos meus cumprimentos de boasvindas. Je m'excuse auprès des Mesdames et Messieurs les Académiciens de notre Maison de m'adresser, en suite, au Professeur Gentilini en Français.

Marc Gentilini est né le 31 juillet 1929 à Compiègne. Il a fait ses études secondaires au Collège des Jésuites de Reims, où il a également commencé la Faculté de Médecine, suivi plus tard par l'externat et l'internat en médecine interne aux Hôpitaux de Paris. Il devient Assistant en Parasitologie, fait son service militaire en Algérie, au Soudan Français (actuel Mali) et au Sénégal. Chef de Clinique et Assistant des Hôpitaux de Paris, il est nommé Professeur Agrégé de Microbiologie en 1966 et travaille aux hôpitaux Claude Bernard et Saint Louis, 
Pitié-Salpêtrière, ele se tornou Professor de Parasitologia e depois de Saúde Pública e de Clínica de Doenças Infecciosas e Tropicais. Em seu serviço nasceu a primeira Unidade de Parasitologia do Inserm em Paris (INSERM 313), na qual foi estabelecida pela primeira vez na França o cultivo in vitro de Plasmodium falciparum. A partir de 1981, com o surgimento da síndrome da imunodeficiência adquirida, o Serviço Clínico da Pitié-Salpêtrière e a Unidade de pesquisa Inserm "Malária e AIDS na África" tornam-se uma estrutura de liderança no tema, resultando em grande expansão da acolhida dos muitos pacientes. Nesse período, um grupo de trabalho sobre a Sida / Aids é criado com a coordenação de Willy Rozenbaum, então seu Chefe de Clínicas, e é do seu Serviço que parte o gânglio no qual Luc Montagnier, Françoise Barre-Sinoussi e Jean-Claude Chermann identificam o vírus da AIDS (depois denominado de HIV-1).

Presidente da Sociedade de Patologia Exótica por quatro anos, ele mobilizou a sociedade científica durante uma cerimônia na Academia de Medicina, na presença do Presidente da República (1997), na qual foram concedidas três medalhas de ouro a dois cientistas e uma irmã de caridade. Ele criou o Curso de Medicina Tropical Santé dans le Monde (que tive a honra de seguir em 1977 e 1978). Esse conjunto constitui uma escola que se torna rapidamente de renome internacional. Muitos estudantes estrangeiros passam pelo Instituto e retornam ao seu País de origem para exercer responsabilidades Hospitalo-Universitárias (Argélia, Benin, Brasil, Congo, Egito, Grécia, Mali, Marrocos, Tailândia, Tunísia entre outros...) ou nos territórios ou Departamentos de ultramar (Guiana Francesa, Martinica...).

Em junho de 1997, foi eleito Presidente da Cruz Vermelha francesa, função que exerceu até dezembro de 2004. Durante seus dois mandatos, ele desenvolveu operaçóes internacionais e, em conjunto com o Organização Pan-Africana contra a Aids (OPALS), instalou, em uma dúzia de estados africanos, os primeiros Centros de Tratamento em regime Ambulatorial (CTA) para doentes com Aids na África e desenvolveu uma campanha para o acesso de todos aos anti-retrovirais.

avant d'être affecté à l'Hôpital de la Pitié-Salpêtrière, en 1970, où il créera le Département des Maladies Infectieuses et Tropicales, et le Laboratoire Central de Parasitologie et Mycologie, s'adressant particulièrement aux pays en développement. Jusqu'à sa retraite en 1997, Gentilini dirigera cet ensemble de disciplines, renforcé par la création 


\section{$\sim 106 \curvearrowright$ \\ ANAIS $d a$ ACADEMIA NACIONAL DE MEDICINA \\ Volume 192 (4), 2021}

Além disso, Marc Gentilini é, desde 1991, Membro da Academia de Medicina, que presidiu em 2008. Ele foi membro da Comissão Consultiva Nacional de Direitos Humanos $(\mathrm{CNCDH})$ por quatro anos, membro do Primeiro Colégio da Alta Autoridade contra a Discriminaçáo e para a Igualdade (HALDE), Presidente da Academia Francesa da Água, por 12 anos, membro da Academia de Ciências do Ultramar, desde 1996, membro do Conselho de Administração da Fundação Chirac para Acesso à Saúde de Qualidade para Todos e para a luta contra os medicamentos falsificados, entre outras funções. ${ }^{2}$

Ele preside hoje a Organização PanAfricana contra a AIDS, cujo alcance se expandiu à toda patologia da mãe e da criança tornando-se Fondation Pan-Africaine pour la Santé, abrigada no seio da Fondation Académie de Médecine.

$\mathrm{Eu}$ queria agora me permitir dizer algumas palavras ao meu Mestre e amigo Marc Gentilini em Francês.

Je m'adresse maintenant à mon Maître et ami, le Professeur Marc Gentilini.

Monsieur et cher confrère et ami. Je suis arrivé dans votre service en septembre 1977 , sept ans après sa création. Je venais d'avoir 25 ans et j'avais fait une année d'internat et une autre comme résidant dans un Service de Médecine Interne et Rhumatologie à l'École de Médecine et Chirurgie de Rio. Je pense vous avoir rencontré, pour la première fois, dans votre bureau situé dans le même vieux bâtiment occupé par le Service du Professeur Godeau. J'étais accompagné de Mme. le Dr.

de l'Institut Santé et Développement. À la Pitié-Salpêtrière, il devient professeur de Parasitologie, puis de Santé Publique et de Clinique des Maladies Infectieuses et Tropicales. Dans son service, la première Unité de Parasitologie Inserm a été créé à Paris (INSERM 313), où la culture in vitro de Plasmodium falciparum a été implantée pour la première fois en France. À partir de 1981, avec l'émergence du syndrome d'immunodéficience acquise (SIDA), le Service Clinique de la Pitié-Salpêtrière et l'unité de Recherche Inserm "Paludisme et sida en Afrique " deviennent une structure d'animation sur le sujet, ce qui se traduit par une grande expansion de l'accueil des nombreux patients. Durant cette période, un groupe de travail sur le SIDA est crée sous la coordination de Willy Rozenbaum, alors son Chef de Clinique, et c'est de son Service qu'est parti le ganglion qui a permis à Luc Montagnier, Françoise Barre-Sinoussi et Jean-Claude Chermann, d'identifier le virus du SIDA (appelé plus tard VIH-1). 
Monique Bonhomme, médecin gynécologue, épouse du rhumatologue et généraliste $D r$. Jean Bonhomme et sour de Nicole Milhaud, filles du grand Chef d'orchestre Milhaud. Permettez-moi de vous raconter cette histoire des origines de mon arrivée dans votre Service. Nicole était amie et collègue de profession de Maître Gui Ladvocat Cintra, Franco-Brésilien ami de mon père et voisin de notre maison de campagne à Petrópolis,

${ }^{2}$ Président de la Société de Pathologie exotique pendant quatre ans, il a mobilisé la société scientifique lors d'une cérémonie à l'Académie de Médecine, en présence du Président de la République (1997), au cours de laquelle trois médailles d'or ont été décernées à deux scientifiques et une soeur de charité. Il a crée le Cours de Médecine Tropicale "Santé dans le Monde" (que j'ai eu l'honneur de suivre en 1977 et 1978). Cet ensemble constitue une école qui acquiert rapidement une renommée internationale. De nombreux étudiants étrangers passent par l'Institut et retournent dans leur pays d'origine pour exercer des responsabilités Hospitalo-Universitaires (Algérie, Bénin, Brésil, Congo, Egypte, Grèce, Mali, Maroc, Thaïlande, Tunisie, entre autres...) ou dans le territoires ou départements d'outremer (Guyane, Martinique...).

En juin 1997, il est élu Président de la Croix-Rouge Française, fonction qu'il occupe jusqu'en décembre 2004. Au cours de ses deux mandats, il développe des opérations internationales et, avec l'Organisation Panafricaine de Lutte contre le Sida (OPALS), met en place, dans une douzaine d'États Africains, les premiers Centres de Traitement Ambulatoire (CTA) pour les malades du SIDA en Afrique et développe une campagne pour l'accès aux antirétroviraux pour tous.

Par ailleurs, Marc Gentilini est membre de l'Académie de Médecine depuis 1991, qu'il a présidée en 2008. Il a été membre de la Commission Nationale Consultative des Droits de l'Homme (CNCDH) pendant quatre ans, membre du Premier Collège de la Haute Autorité contre les discriminations et pour l'égalité (HALDE), Président de l'Académie Française de l'Eau, pendant 12 ans, membre de l'Académie des Sciences d'Outre-Mer, depuis 1996, membre du Conseil d'Administration de la Fondation Chirac pour l'accès à une Santé de Qualité pour Tous et pour la Lutte Contre les Médicaments Contrefaits, entre autres fonctions.

Il préside aujourd'hui l'Organisation Panafricaine de Lutte contre le Sida, dont la portée s'est élargie à toutes les pathologies de la mère et de l'enfant, devenant la Fondation Pan-Africaine pour la Santé, hébergée au sein de la Fondation Académie de Médecine.

Je voudrais maintenant me permettre de dire quelques mots à mon Maître et ami Marc Gentilini en Français. 
ville où j'ai commencé mes études de médecine. Vers la conclusion du cours médical, j'avais commencé à me préparer pour passer le célèbre examen ECFMG - qui habilite les médecins étrangers à la résidence médicale aux EUA - quand Gui a convaincu mon père que la France était " un bien meilleur endroit " pour étudier et qu'il pourrait maider en appuyant une demande de bourse auprès $d u$ gouvernement Français au Consulat de France où il travaillait. C'est alors que j'ai appris que j'aurais plus de chances si je choisissais un service de médecine tropicale pour un stage de spécialité. Quand Mr Ladvocat Cintra a demandé de l'aide à son amie Mme Milhaud pour identifier un point d'accueil à Paris, sa soeur Monique Bonhomme n'a pas hésité : "Il doit aller étudier avec le Professeur Gentilini à Paris ". Mon père était si enthousiasmé par la perspective, qu'il m'a dit: si ce professeur t'accepte, il ne faut pas attendre la réponse du Gouvernement Français, je t'aiderai jusqu'à ce que la bourse soit approuvée... elle ne l'a pas été et je fus financé par le CNPq, le conseil National de Recherche Brésilien, pendant la majeure partie de mon séjour. ${ }^{3}$

Je me souviens de votre présence toujours élégante, et votre attitude toujours attentive à tous les mouvements duservice dont la renommée et le prestige croissaient progressivement en France et en Europe. Vous avanciez toujours pressé, et à pas fermes, dans les couloirs du service, où vous étiez habituellement suivi par des assistants, la surveillante et internes et stagiaires qui souhaitaient vous dire quelques mots avant que vous ne disparaissiez pour une réunion externe. Je me souviens vous avoir vu habillé d'un costume, toujours de même coupe, noir ou bleu très foncé, assorti d'une chemise impeccablement blanche et une cravate noire (ou bleue très foncée). Je peux même parier que ce sera votre tenue pendant la cérémonie d'aujourd'hui (ce qui fut le cas).

${ }^{3}$ Dirijo-me agora ao meu Mestre e amigo, Professor Marc Gentilini.

Professor e caro colega e amigo. Cheguei ao seu serviço em setembro de 1977, sete anos após sua criação. Eu tinha acabado de completar 25 anos e havia feito um ano de internato e outro como residente do Departamento de Clínica Médica e Reumatologia da Faculdade de Medicina e Cirurgia do Rio. Acho que o conheci, pela primeira vez, em seu escritório no mesmo velho prédio ocupado pelo Serviço do Professor Godeau. Fui acompanhado pela Dra. Monique Bonhomme, ginecologista, esposa do reumatologista e clínico geral Dr. Jean Bonhomme e irmã de Nicole Milhaud, filhas do grande maestro Milhaud. Deixe-me contar-lhe 
J'ai le souvenir marquant des fameuses réunions des jeudis matin avec les assistants, la Surveillante générale et les stagiaires les plus anciens, comme Ashraf Mogahed et Riadh BenIsmail. Je me souviens de ma fierté quand j'ai été admis à rejoindre ce groupe pour les sessions que j'ai appris à nommer "le Conseil des Ministres " avec votre assistant Gérard Niel. Elles étaient suivies de la réunion du staff (ou simplement le Staff) qui avait lieu de $11 \mathrm{~h}$ à $13 \mathrm{~h}$ précises, dans la salle d'attente des patients du Pavillon Laveran, construit pour abriter votre Service à partir du début des années 1980. La salle était réaménagée avec les chaises rangées en $U$ ou $L$ avec une grande table basse centrale sur lesquelles reposaient des énormes pots de café et

esta história das origens da minha chegada ao seu Serviço. Nicole era amiga e colega de profissão do adovogado Gui Ladvocat Cintra, franco-brasileiro amigo de meu pai e vizinho de nossa casa de campo em Petrópolis, cidade onde comecei meus estudos médicos. Perto da conclusão do curso de medicina, comecei a me preparar para o famoso exame ECFMG - que qualifica os médicos estrangeiros para a residência médica nos EUA - quando Gui convenceu meu pai de que a França era "um lugar muito melhor" para estudar e que ele poderia me ajudar apoiando um pedido de bolsa de estudos do governo francês no Consulado da França onde ele trabalhava. Foi quando eu soube que teria mais chances se escolhesse um Serviço de Medicina Tropical para fazer um estágio de especialidade. Quando o Dr. Ladvocat Cintra pediu ajuda à sua amiga Dra. Milhaud para identificar um ponto de recepção em Paris, sua irmã Monique Bonhomme não hesitou: "ele deve ir estudar com o Professor Gentilini em Paris". Meu pai ficou táo empolgado com a perspectiva, que me disse: - se esse professor te aceitar, não devemos esperar a resposta do governo Francês. Vou te ajudar até que a bolsa seja aprovada... ela não o foi e eu fui financiado pelo CNPq, o Conselho Nacional de Desenvolvimento Científico e Tecnológico, do Brasil, durante a maior parte da minha estadia.

Recordo-me de sua presença sempre elegante, e a sua atitude sempre atenta a todos os movimentos do Serviço cuja fama e prestígio cresciam progressivamente na França e na Europa. Com seus passos firmes, o Senhor avançava apressado pelos corredores do Serviço, onde geralmente era seguido por assistentes, a surveillante e internos e estagiários que queriam lhe dizer algo antes do Senhor desaparecer para uma reunião externa. Lembro-me de vê-lo vestido com um terno sempre do mesmo corte, preto (ou azul muito escuro), com uma camisa branca impecável e uma gravata preta (ou azul muito escuro). Posso apostar que vai ser o seu traje durante a cerimônia de hoje (foi... ). 
des plateaux bourrés de savoureux croissants et pains au chocolat chauds. Dans l'audience il $y$ avait des visiteurs issus de tous les coins de France et parfois de l'étranger. C'est lá que j'ai connu Messieurs Ambroise-Thomas, Bourré, Charmot, Mouchet, Rodhain, Mme Leger et le Córdobais Hugo Pizzi, qui deviendra un très bon ami. Aucune présentation ne devait dépasser 10 ou 15 minutes, etje ne me souviens que d'une seule fois ò̀ cela s'est produit: un externe faisait une si belle présentation, si riche de superbes photographies obtenues en plongée sous-marine dans les îles de Polynésie Française, que, appelé pour recevoir un Chef d'État Africain qui était passé vous voir, vous avez demandé à l'étudiant d'arrêter son exposé jusqu'à votre retour. ${ }^{4}$

${ }^{4}$ Tenho uma vívida memória das famosas reunióes matinais de quinta-feira com os seus assistentes, a Surveillante Générale e os estagiários mais antigos, como Ashraf Mogahed e Riadh Ben-Ismail. Lembro-me de meu orgulho quando fui admitido, como membro desse grupo, para as sessóes que aprendi a chamar, com o seu assistente Gérad Niel, de "Conselho de Ministros". Seguiam-se as reuniōes de staff (ou simplesmente Staff), que decorriam das $11 \mathrm{~h} 00$ às $13 \mathrm{~h} 00$ em ponto, na sala de espera de pacientes do Pavillon Laveran (construído para alojar o seu Departamento desde o início da década de 1980), reorganizada com as cadeiras dispostas em U ou L, com uma grande mesa central sobre a qual repousavam enormes bules de café e travessas abarrotadas de croissants e pains au chocolat quentes e saborosos. Na plateia havia visitantes de toda a França e às vezes do exterior. Foi onde conheci os Professores Ambroise-Thomas, Bourré, Charmot, Nicole Leger, Rodhain e o Cordobês Hugo Pizzi, que se tornaria um grande amigo. Nenhuma comunicação devia ultrapassar 10 ou 15 minutos, e só me lembro de um momento em que isso aconteceu: Um estudante de medicina fez uma apresentação tâo bonita e rica em magníficas fotografias obtidas em mergulhos nas ilhas da Polinésia Francesa, que, tendo sido chamado para receber um Chefe de Estado Africano que veio lhe ver no Serviço, o Senhor pediu que o aluno parasse de fazer sua apresentação até o seu retorno.

Para entender a impressão que sua presença me deixou, é preciso evocar minhas lembranças dos anos 1960 a 1963, quando, com a idade de 8 a 11 anos, eu guardava cuidadosamente em uma estante do quarto que dividia com meu irmão mais novo, a coleção da revista "Selections from Readers Digest", que meu pai assinava. Naquela época, brinquedos e livros eram escassos, tanto quanto o dinheiro, e eu procurava ler tudo o que chegava em minhas mãos. Era um grande prazer para mim ler todas as seçôes da revista, incluindo uma chamada "Meu tipo inesquecível". Confesso-lhe que foi tão forte a impressão que me causaram as suas seriedade, reputação, 
des années 1960 à 1963, quand, à l'âge de 8 à 11 ans, j'avais, soigneusement rangé sur une étagère dans la chambre que je partageais avec mon frère cadet, la collection du magazine "Sélections du Readers Digest ", auquel mon père était abonné. A cette époque les jouets et les livres étaient aussi rares que l'argent, et j'essayais de lire tout ce qui me tombait entre les mains. C'était pour moi un grand plaisir de lire chaque rubrique du magazine, dont une nommée "Mon type inoubliable". Je vous avoue que votre sérieux, votre réputation, votre compétence reconnue, vos attitudes respectueuses et soucieuses $d u$ bon fonctionnement $d u$ service et $d u$ bienêtre des malades ont laissé sur moi une si forte impression que si j'avais à écrire un jour deux articles dans cette session, l'un serait à propos de mon père et l'autre vous concernerait...

Monsieur Gentilini, avant de terminer ces mots de bienvenue, je voudrais dire que même s'il est probable que l'enquête historique des Honorários Estrangeiros depuis la création de notre Maison en 1829, faite par notre archiviste Paula Padilha Cerqueira, comporte des erreurs, en principe, vous êtes au nombre de 369 (le premier, un

reconhecida competência e atitudes de respeito e preocupação com o bom funcionamento do serviço e o bemestar dos doentes, que se tivesse que escrever dois artigos nessa sessão do periódico, um seria sobre meu pai e o outro seria sobre o senhor...

Professor Gentilini, antes de terminar estas palavras de boas-vindas, gostaria de dizer que ainda que seja provável que a investigação histórica dos Honorários Estrangeiros desde a criação da nossa Casa em 1829, feita pela nossa arquivista Paula Padilha Cerqueira, tenha falhas, em princípio, os Senhores são 369 (o primeiro, um inglês, em 1855). Quarenta estão vivos (o número máximo permitido). Do total, 79 são franceses, sendo o primeiro deles Louis Pasteur, nomeado em 18/11/1884. O Senhor está em boa companhia: Pierre AmbroiseThomas, Jean Bernard, Emile Brumpt, Christian Cabrol, Albert Calmette, Jean Civatte, Marie Curie, Alice Datry, Robert Degos, Andre Delmas, Emile Emery, Jean Géraud Lafargues, Charles Alphonse Laveran, Pierre Lepine, Paul Milliez, Charles Richet, entre outros.

O Senhor pode imaginar, portanto, nossa satisfação e honra em recebê-lo como um desses grandes. Para mim, é um prazer pessoal poder anunciar, em nome dos meus Confrades brasileiros, pela tricentésima septuagésima nona vez a um Honorário Estrangeiro, bem-vindo à Academia Nacional de Medicina !

Pour comprendre l'impression que votre présence m’a laissé, il faut évoquer mes mémoires 
Anglais, en 1855). Quarante sont en vie (le nombre maximum admis). Du total, 79 sont français, le premier d'entre eux, fut Louis Pasteur, nommé le 18/11/1884. Vous êtes en bonne compagnie : Pierre Ambroise-Thomas, Jean Bernard, Emile Brumpt, Christian Cabrol, Albert Calmette, Jean Civatte, Marie Curie, Alice Datry, Robert Degos, Andre Delmas, Emile Emery, Jean Géraud Lafargues, Charles Alphonse
Laveran, Pierre Lepine, Paul Milliez, Charles Richet, entre autres.

Vous imaginez donc, certainement, notre contentement et honneur en vous recevant comme un de ces grands. Pour moi, c'est un plaisir personnel de pouvoir annoncer, au nom de mes Confrères Brésiliens, pour la trois centième soixantedix neuvième fois à un Honorário Estrangeiro, bienvenu à l'Academia Nacional de Medicina!

Merci beaucoup! 